\title{
Benefits of a commercial solid-state fermentation (SSF) product on growth performance, feed efficiency and gut morphology of juvenile Nile tilapia (Oreochromis niloticus) fed different UK lupin meal cultivars
}

by Bowyer, P.H., El-Haroun, E.R., Salim, H.S. and Davies, S.J.

Copyright, publisher and additional Information: This is the author accepted manuscript. The final published version (version of record) is available online via Elsevier.

This version is made available under the CC-BY-ND-NC licence:

https://creativecommons.org/licenses/by-nc-nd/4.0/legalcode

Please refer to any applicable terms of use of the publisher

DOI: https://doi.org/10.1016/j.apsoil.2019.103433 
1 Benefits of a commercial solid-state fermentation (SSF) product on growth performance, feed

2 efficiency and gut morphology of juvenile Nile tilapia (Oreochromis niloticus) fed different

3 UK lupin meal cultivars

4

5 Bowyer ${ }^{1}$, P. H. El-Haroun ${ }^{2, *}$, E.R., Salim², H.S., Davies ${ }^{1}$, S.J.

$6 \quad{ }^{1}$ Fish Nutrition and Aquaculture Unit, Harper Adams University, Newport, Shropshire,

7 United Kingdom

8

$9 \quad{ }^{2}$ Fish Nutrition Research Laboratory, Animal production department, Faculty of Agriculture,

10 Cairo University

11

123

13

14 Corresponding author: elharoun@gmail.com

15

16

17

18

19

20

21

22

23

24

25

26

27

28 
ABSTRACT

30

31

32

A nutritional investigation was conducted to determine whether growth performance, feed efficiency and midgut morphology of Nile tilapia is affected by United Kingdom cultivars of Yellow Lupin (Control, Y) (YLC) or Blue Lupin (Control, B) (BLC) inclusions compared to the addition of a commercial solid-state fermentation product (SSF) in separate dietary treatments for both lupin cultivars (YLS and BLS). After 49 days of feeding, tilapia receiving SSF supplemented diets (YLS \& BLS) exhibited significantly greater weight gain (WG), specific growth rate (SGR), feed conversion ratio (FCR), protein efficiency ratio (PER) and condition factor $(\mathrm{K})$ compared to YLC or BLC without solid state fermentation. SSF inclusion exhibited significantly improving of enterocyte height within both the first and second half of the experiment $(P<0.05)$. The surface area of the midgut was not affected by lupin type or SSF $(P>0.05)$; although a potential response over time was apparent in the YLS group. Enterocyte microvilli were significantly wider in fish fed YLC diets $(P<0.05)$, whilst they were significantly longer in the BLC control compared to the YLC control $(P<0.05)$. Microvilli lengths of fish fed YLS were comparable to those receiving BLC diets and close to being significantly longer than those fed YLC alone $(P=0.06)$. Overall, BLC appeared to perform superiorly to YLC; whilst SSF inclusion promoted some desirable production parameters, seemingly most effectively in the YLC diet.

Keywords: Nile Tilapia; Growth; Feed utilisation efficiency; UK lupins; Solid State Fermentation; Gut morphology; Enterocyte microvilli integrity 


\section{INTRODUCTION}

55 In response to the growing necessity to reduce fish meal use, plant proteins have been

56 extensively adopted as the main solution for ensuring protein security within the diets of many

57 aquatic species and poultry, with great successes achieved in the past two decades (Michael et

58 al., 2016; Daniel, 2018). Meanwhile, the volumetric majority of commercially cultured finfish,

59 including tilapias and carps, do not necessarily require marine-derived proteins in their diet

60 (FAO, 2016; Daniel, 2017). However, their increasing production levels will continue to

61 demand a simultaneous increase in the availability of high-quality but cost-effective dietary

62 protein sources. Ingredient selection must be scrutinised to promote a sustainable development

63 of the aquaculture industry and plant proteins should not be exempt from this consideration. In

64 light of high crop importations, particularly of soya, calls are being made within Europe for

65 diversification of protein-sources, for sustenance of the livestock sector (Bowyer et al 2019;

66 Goda et al., 2019; Mercedes et al., 2015; El-Husseiny et al., 2018; Davies et al., 2019, Hassan

67 et al., 2019). Importation to a level of dependency does not ensure protein security and the

68 extended supply chain raises socioeconomic and environmental sustainability concerns such as

69 financial cost, out-sourcing of industrial efforts and employment, little to no control over

70 agricultural practices and the 'carbon-footprint' of transportation. At present, alternative

71 proteins in aquafeeds should begin to no longer be viewed, or categorised, as simply

72 alternatives to fish meal; they should be considered as any ingredient with the potential to

73 outperform the sustainability credentials of any other commercially implemented counterpart.

74 Lupins are seen to be a great potential competitor to soya bean (Bartkiene et al., 2015;

75 Rajeev and Bavitha 2015). They possess a high protein content and due to the multiple species

76 which are available, there is opportunity for cultivation in different climates and soil types;

77 therefore they can be considered an option for many farmers in both developed and developing

78 countries alike (Yeheyis et al. 2012; Mercedes et al. 2015). This is of considerable relevance 
79 in Europe with an increased interest in tilapia production in RAS (Recirculation Aquaculture

80 Systems) and bespoke feed development. Consequently, there is much focus on lupins as a

81 feed crop in the UK for the home and export market for pigs, poultry and fish, including the

82 farming of tilapia.

83 However, with most terrestrial-derived ingredients (mainly plant by-products), there

84 are inherent nutritional limitations when consumed by most of the world's commercially 85 produced finfish species. In many cases, the finfish digestive system has not evolved to 86 encounter specific compounds found within plant-derived ingredients, thus availability of 87 nutrients is directly impinged or functional gut morphology is aggravated in a manner whereby 88 assimilation of nutrients becomes restricted (Krogdahl et al., 2005). With regards to lupins, 89 their non-starch polysaccharide (NSP) content is of particular concern; even after de-hulling, 90 this can remain higher than many other plant-protein competitors (Van Barneveld, 1999).

91 Furthermore, lupins tend to contain significant quantities of oligosaccharides (Van Barneveld, 92 1999), notably a-galactosyl homologues of sucrose which have been demonstrated to impede 93 upon the digestive process in fish (Glencross et al., 2003).

94 Nutritional inferiority of both hulled and de-hulled narrow-leaf lupin (Lupinus 95 angustifolius), compared to soya bean meal, has been previously indicated in Nile tilapia 96 (Oreochromis niloticus), with observations of depreciated growth following increasing 97 inclusions of the lupin products (Chien and Chiu, 2003). Some have highlighted a requirement 98 for breeding programmes and processing approaches to address anti-nutritional factors (ANFs) 99 in lupins (Mercedes et al. 2015) but in vivo biological strategies aimed at degrading these 100 compounds may present a complementary or alternative option.

101 Solid-state fermentation (SSF) involves the microbial fermentation of a substrate in the 102 absence of free-flowing water. Subsequent products may present a multi-faceted approach to 103 continued fermentation within the gastro-intestinal tract of livestock, by providing residual 
104 bioactive components theoretically capable of degrading previously indigestible dietary 105 fractions. Enhanced animal performance has previously been observed following inclusion of 106 solid-state fermentation products in more contemporary formulations for poultry (Hooge et al., 107 2010) and Nile tilapia Oreochromis niloticus (Hassaan et al., 2017). Diógenes et al (2018) 108 investigated commercial exogenous enzymes and the SSF product Synergen ${ }^{\mathrm{TM}}$ produced by 109 Alltech, USA with very promising results on the performance of turbot (Scophthalmus 110 maximus) juveniles fed distillers' dried grains with solubles (DDGS) based diets.

111 In terms of enhancing the nutritional value of lupins, a recent study, investigating the pre112 treatment of lupin with Lactobacilli for inclusion in barramundi (Lates calcarifer) diets, 113 reported that nutritional value of the ingredient could be significantly improved through such 114 fermentation methods (Binh Van et al., 2015). To the authors' knowledge, no studies have yet 115 examined lupins in conjunction with solid-state fermentation products in finfish diets. 116 Furthermore, both lupins and exogenous bioactive supplements (asides from probiotics) have 117 sparsely been investigated with regards to their effects upon gut morphology, despite the 118 organ's integral function in assimilating nutrients and pathogen defence; hence the reasoning 119 behind this study. The midgut contains enzymes from the pancreas, intestinal wall and liver. 120 These enzymes attack proteins, lipids, and carbohydrates which obviously affect feed 121 efficiency utilization and consequently growth performance of fish, thus midgut 122 histomorphology was appraised at the start-, mid- and end-point of the trial to identify any 123 temporal responses to the experimental ingredients. Furthermore, the ultrastructure of the 124 midgut brush border was examined at the end of the study to identify any adverse effects upon 125 the dietetically and nutritionally sensitive microvilli. Carcass composition, along with 126 haematological and serological indices of health and immune status were also examined for 127 tilapia. Thus, the present investigation was conducted to evaluate the performance and midgut 128 morphology of Nile tilapia fed diets containing either yellow lupin (Lupinus luteus) or blue 
lupin (Lupinus angustifolius) meals with and without inclusion of a solid-state fermentation product (Synergen ${ }^{\mathrm{TM}}$; Alltech Inc., KY, USA).

MATERIALS AND METHODS

132

133

134

\section{Experimental system and animals}

The nutritional trial was conducted within a Recirculating Aquaculture System (RAS) facility designed for nutrition trials with replicate tanks. For the study, YY super-male, black Nile tilapia (Oreochromis niloticus) was obtained from North Moore Tilapia (Lincolnshire, UK). The fish were stocked into $80 \mathrm{~L}$ tanks within a $\sim 2200 \mathrm{~L}$ recirculating system which supplied a flow rate of $\sim 600 \mathrm{~L} / \mathrm{hr}$. Acceptable water quality was maintained by biological and mechanical filtration, temperature was maintained at $26.0{ }^{\circ} \mathrm{C} \pm 1$, dissolved oxygen was maintained above $76.0 \%$ and a $12 \mathrm{hrs}$ light photoperiod was implemented with fluorescent lights and timers. During a 4 week adaptation period, the fish were fed a BioMar Efico Enviro (BioMar, DK) diet at $\sim 2 \%$ body weight (BW) per day. Following adaptation and grading, selected individuals were restocked into replicate groups of 50 individuals $(n=3)$, with resulting average initial fish weight of $36.22 \mathrm{~g} \pm 0.16$; corresponding to a stocking density of $20.12 \mathrm{~kg} / \mathrm{m}^{3} \pm 0.13$

\section{Experimental ingredients and diets}

De-hulled kernel meal from narrow-leaf blue lupin (Lupinus angustifolius cv. Sanabor) and yellow lupin (Lupinus luteus cv. Pootalong) were supplied by Soya UK (Hampshire, UK), after de-hulling and milling by Alvan Blanch (Wiltshire, UK). These crops were cultivated in the U.K. as part of the Lupins in UK Agriculture and Aquaculture (LUKAA) initiative (Innovate UK). The solid-state fermentation product, Synergen ${ }^{\mathrm{TM}}$ (SSF), was kindly supplied by Alltech Inc. (KY, USA). Four experimental diets were formulated to satisfy all known nutrient requirements of Nile tilapia (NRC, 2011) and be isonitrogenous $\left(\mathrm{N}^{*} 6.25\right)$, isolipidic and isocaloric. These were two basal diets, with $15 \%$ yellow or narrow-leaf blue lupin 
inclusion to form reference (control) diets at a lupin level compliant with successful previous inclusions for warm water fish species). Synergen ${ }^{\mathrm{TM}_{-}}\left(\right.$Alltech $\left.{ }^{\circledR}\right)$ supplemented diets were manufactured by including the SSF product at $0.1 \%$ at the expense of corn starch (Table 1 ). The diets were formulated using feed formulation software (FeedSoft ${ }^{\mathrm{TM}}$ FeedSoft corp., Dallas TX, USA) with inputted data from analysed ingredients actually employed.

\section{Diet preparation}

The ingredients were thoroughly combined in a Hobart Legacy mixer (Hobart Food Equipment, HL1400-10STDA; AU), for $30 \mathrm{~min}$. Oil was subsequently added to the ingredient mix and left to combine homogenously for $30 \mathrm{~min}$, followed by the addition of tepid water to achieve an appropriate consistency for pellet manufacture. Once an appropriate consistency was achieved, the dietary mix was immediately cold-press extruded (PTM Extruder System, P6; Devon, UK) and manually cut to form $2 \mathrm{~mm}$ diameter pellets. The moist pellets were ovendried at $35{ }^{\circ} \mathrm{C}$ (Genlab, MINO $200 \mathrm{~F}$; Cheshire, UK). The diets were packaged in sterilised containers and kept at room temperature $\left(\sim 15^{\circ} \mathrm{C}\right)$ until used.

\section{Chemical composition}

Proximate compositional analysis was conducted according to standard AOAC (2016) procedures: moisture by oven-drying at $105^{\circ} \mathrm{C}$; crude protein via Kjeldahl method with a Gerhardt Kjeldatherm 40 digestion block and automated Vapodest 40 distillation unit (Gerhardt Laboratory Instruments; DE) (N x 6.25); crude lipid by hot-solvent extraction with a 6-place Soxtherm and Multistat control system (Gerhardt Laboratory Instruments; DE); ash via incineration at $550{ }^{\circ} \mathrm{C}$ for $12 \mathrm{hrs}$. The sum of moisture, crude protein, crude lipid and ash (\%) was subtracted from 100 to calculate nitrogen-free extract (NFE).

\section{Feeding and biomass sampling}


179 fixed rations between 2.0 and $3.5 \% \mathrm{BW}$ per day, which were incrementally reduced as the fish

180 grew. The fish were weighed in bulk, by tank, on a weekly basis. This was performed, to an

181 accuracy of 1 gram. Feeding rations were subsequently calculated for the following 6 days.

\section{Performance evaluation}

Weight gain $(\mathrm{g})$ specific growth rate $(\mathrm{g} / \mathrm{d})$, protein efficiency ratio and condition factor

were recorded for all fish from each aquarium at the initiation and the termination of the experiment was calculated using the subsequent formulae:

Weight gain $(\mathrm{WG})=$ final body weight $(\mathrm{g})$ - initial body weight $(\mathrm{g})$.

Initial body weight; W2 = Final body weight and T= period of study (60 days).

Protein Efficiency Ratio (PER) =WG (g)/Protein intake (g).

Condition Factor $=\mathrm{K}$ value $=($ body weight, $\mathrm{g}) /\left(\right.$ body length, $\left.\left.\mathrm{cm}^{3}\right) \times 100\right)$

191

192

193

194

195

196

197

198

199

200

201

202

\section{Carcass composition}

At day 49, sampling for whole carcass was performed by sacrificing and pooling $\geq 200$ $\mathrm{g}$ of wet fish per tank $(n=3)$. The proximate composition of the carcasses was determined according to AOAC (2016)

\section{Haematological parameters}

At day 49, three fish per tank $(n=9)$ were sedated in buffered tricaine methanesulfonate (MS222) and blood was collected from the caudal vein. Haemoglobin levels (g/dl) were determined utilising Drabkin's cyanide-ferricyanide solution (Sigma) as described by Rawling et al. (2012). Haematocrit (\% PCV) was determined using the microhaematocrit method described by Brown (1988). Serum was prepared in accordance with Rawling et al. (2012). Serum glucose $(\mathrm{mg} / \mathrm{dl})$ was measured by the Trinder method, a turbidimetric coupled-enzyme assay. In brief, phosphate buffer (100 mM, pH 7.0) containing $0.016 \%$ (w/v) 4- 
203 Aminoantipyrine, $2 \times 10^{-4} \%(\mathrm{w} / \mathrm{v})$ peroxidase, $0.105 \%(\mathrm{w} / \mathrm{v})$ phenol and $0.1 \%(\mathrm{v} / \mathrm{v})$ Tween-

20420 was created as a colour reagent (all reagents Sigma). Three ml of colour reagent and $50 \mu 1$

205 of serum were mixed and incubated for $15 \mathrm{~min}$ at $28{ }^{\circ} \mathrm{C}$, rapidly cooled, then read at $550 \mathrm{~nm}$.

206 Serum lysozyme activity $(\mathrm{U} / \mathrm{ml})$ was analysed in accordance with methods described by

207 Demers and Bayne (1997), which involved the lysis of Gram-positive Micrococcus

208 lysodeikticus and measured by a turbidimetric assay.

209 Midgut histology

210 Specimens for mid gut evaluation were sampled from the initial stock at day $0(n=9)$,

211 followed by sampling of 3 fish per tank at days 26 and $49(n=9)$, for light microscopy (LM).

212 Specimens for transmission electron microscopy (TEM) were also obtained from the fish 213 sampled at 49 days.

214 For light microscopy preparation (LM), the specimens were fixed in $10 \%$ formalin

215 which was replaced by $70 \%$ ethanol after $24 \mathrm{hrs}$. The specimens were subsequently dehydrated

216 in graded ethanol concentrations then embedded in paraffin wax. Multiple sections were cut

217 from each sample at $5 \mu \mathrm{m}$ thicknesses (Leica, RM2235; Buckinghamshire, UK) and stained

218 with haematoxylin and eosin (Leica, Autostainer XL; Buckinghamshire, UK). The specimens

219 were screened with a Leica DMIRB microscope and Olympus E410 digital SLR camera.

220 Enterocyte heights $(\mu \mathrm{m})$ were measured throughout intestinal folds. Functional surface area

221 was evaluated by measuring the outer mucosal (OP) and inner epithelial (IP) perimeters of

222 cross-sections, to calculate perimeter ratio (PR) (arbitrary unit: AU) as follows:

223 Perimeter ratio (PR) = OP / IP (As described by Bowyer et al., 2019)

224 For Transmission Electron Microscopy (TEM) appraisal, the samples were processed in 225 accordance with methods detailed by Dimitroglou et al. (2009). In brief, specimens were fixed 226 in sodium cacodylate-buffered $2.5 \%$ glutaraldehyde then post-fixed in sodium cacodylate227 buffered $1 \%$ osmium tetroxide $\left(\mathrm{OsO}_{4}\right)$. Dehydration was conducted in graded levels of ethanol; 
thereafter infiltration, curing and polymerisation were conducted with low viscosity resin premix (AGR1078, Agar Scientific; Essex, UK).

230 Ultra-thin sectioning $(\sim 80 \mathrm{~nm})$ was conducted using a Reichert-Jung Ultracut E ultratome

231 (Leica; Buckinghamshire, UK) with a diamond knife (Microstar Tech.; TX, USA).

232 Staining was conducted on copper grids using saturated uranyl acetate with secondary 233 contrasting using lead citrate solution.

234 The specimens were screened with a $120 \mathrm{kV}$ JEOL JEM-1400 transmission electron 235 microscope (Tokyo, Japan) with a Gatan Orius 830 imaging system (CA, USA).

236 Microvilli heights (MVH) $(\mu \mathrm{m})$ and microvilli diameters (MVD) $(\mu \mathrm{m})$ were measured using 237 micrographs orientated in a cross-section fashion. Micrographs providing an aerial view of the 238 brush border were used to measure microvilli counts (MVCT) (no. $\left./ \mu \mathrm{m}^{2}\right)$ using $1 \mu \mathrm{m}^{2}$ quadrants 239 placed upon standardised co-ordinates. Estimated total absorption surface area (TAS), 240 expressed as $\mu \mathrm{m}^{2}$ per $1 \mu \mathrm{m}^{2}$ foot-print, was calculated using the previous parameters as follows:

241 TAS $\left(\mu \mathrm{m}^{2} / 1 \mu \mathrm{m}^{2}\right)=\left((2 \pi \times 1 / 2 \mathrm{MVD} \times \mathrm{MVL})+\left(2 \pi \times 1 / 2 \mathrm{MVD}^{2}\right)\right) \times$ MVCT

\section{Economical evaluation}

The economic value of the diets was determined according to (Abdel Rahman et al. 2010

244 and Salama et al. 2010) using the following equations:

245 Feed Conversion Ratio $(\mathrm{FCR})=$ Feed intake $(\mathrm{FI})(\mathrm{g}) / \mathrm{WG}(\mathrm{g})$.

246 Relative feed cost $/ \mathrm{kg}$ fresh fish $=$ Values of feed cost $/ \mathrm{kg}$ fresh fish $/$ the minimum value of the 247 same parameter.

248 Feed cost $1 \mathrm{~kg}$ gain $(\$)=$ Feed intake per $\mathrm{kg}$ gain $(\mathrm{FCR}) \times \operatorname{cost} / \mathrm{kg} \operatorname{diet}(\$)$.

249 Economic conversion rate $(\mathrm{ECR})=$ Cost of diet $\left(\$ \mathrm{~kg}^{-1}\right) \times$ Feed conversion ratio $(\mathrm{FCR})$.

\section{Statistical analyses}

All statistical analyses were performed using Sigma Plot 13.0 (SyStat Software Inc.;

252 IL, USA). All values expressed as percentages herein were arcsine-transformed prior to 
statistical analysis. Fish and feed performance, carcass composition, haemato-serological and

254 midgut ultrastructural parameters were analysed via Two-Way Analysis of Variance (ANOVA)

255 with Fisher's LSD Method for pair wise multiple comparisons. Variables tested were lupin 256 type (YL and BL) and SSF presence (0 and 0.1\% SSF, i.e. control and SSF inclusion), with a 257 test of interaction between these two variables. Enterocyte height (EH) and absorptive surface 258 area (PR) were analysed via Three-Way ANOVA with Fisher's LSD Method. Variables tested 259 were lupin type, SSF presence and time (day 0, 26 and 49), with interactions assessed between 260 the three variables. Significant effects of time alone upon all treatments collectively are not 261 presented in figures herein. Analyses were performed upon ranked means, where data 262 expressed non-normal distribution and are referred to as such within. Statistical significance 263 was considered as $P \leq 0.05$ throughout.

264 Fish protocols were approved by the Institutional Animal Care and Welfare Committee 265 and conforming to European Union statutory regulations for Animal Scientific Procedures 266 (APC's).

267 RESULTS

268 Growth performance, feed efficiency and fish condition results are displayed in Table 269 2. Average final fish weight (FW), weight gain (WG) and specific growth rate (SGR) were all 270 significantly increased by SSF $\left(\right.$ Synergen $\left.^{\mathrm{TM}}\right)$ inclusion $(P=0.02, P=0.02, \mathrm{P}=0.03$, 271 respectively); no significant effects of lupin type, or lupin type-SSF interaction were observed.

272 Significant effect was also detected upon the improvement of FCR with the SSF product 273 inclusion against the corresponding control lupin diets fed to tilapia. Furthermore, no 274 significant effects of SSF, lupin type or an interaction between the two dietary variables upon 275 PER $(P=0.07)$ No significant effects upon K-factor $(K-F)$ were observed.

276 Carcass composition appeared not to be affected by lupin type, SSF inclusion or interaction 277 between the two dietary variables; the results are displayed in Table 3. 
278 Haematological analysis of haematocrit (\% PCV), haemoglobin (g/dl), serum glucose (mg/dl)

279 and serum lysozyme $(\mathrm{U} / \mathrm{ml})$ did not appear to show any significant responses to the dietary 280 variables; the results of which are displayed in Fig. 1.

281 Enterocyte Height (EH) results are displayed in Fig. 2. No significant effect of lupin type or 282 SSF inclusion alone was identified upon ranked EH. However, time was observed to 283 significantly affect $\mathrm{EH}(P=0.02)$, with the overall ranks at day 26 significantly differing from 284 day $0(P=0.01)$ and likewise, ranks at day 49 differing from day $0(P=0.01)$. Within the 285 controls, EH was observed to not be significantly different between days 0 and 26, however 286 the values were indicated to be significantly different between days 26 and $49(P=0.03)$ and 287 days 0 and $49(P=0.01)$. With the SSF diets, a significant difference in EH was observed 288 between days 0 and $26(P<0.01)$ and days 26 and $49(P=0.02)$, however no difference was 289 observed between days 0 and 49. Consequently, a significant interaction between SSF inclusion 290 and time was observed upon $\mathrm{EH}(P=0.01)$. The controls displayed significantly lower EH than 291 the SSF treatments at day $26(P=0.02)$, whilst the trend was significantly the inverse at day 292 $49(P=0.04)$.

293 Perimeter Ratio (PR) results are displayed in Fig. 2. Time was observed to significantly affect 294 grouped PR alone between days 0 and $26(P<0.01)$ and consequently days 0 and $49(P<0.01)$ 295 but no difference was detected between the overall values recorded between days 26 and 49 . 296 Significant effects of time upon PR were independent of lupin type and SSF. However of note, 297 a near significant interaction between lupin type, SSF inclusion and time was detected $(P=$ 298 0.06), as a consequence of a numerical decrease in PR within the YLS group between day 26 and 49, indicating an increase in relative surface area.

300 Midgut ultrastructure results are displayed in Table 4 and micrographs are presented in Fig. 3013 . No significant effects of any dietary variables were observed upon microvilli counts (MVCT) $302(P>0.05)$. However counts were numerically higher in the BL-fed fish, attributable to 
microvilli diameter (MVD) being significantly lower in this group $(P=0.03)$. No effect of SSF

304 inclusion or interaction between the dietary variables was detected upon MVD. No significant

305 effect of lupin type or SSF inclusion alone was observed upon microvilli height (MVH).

306 However, a significant interaction between lupin type and SSF inclusion was detected $(P=$

307 0.03). The difference was detected to lie between the control diets, in the absence of SSF, with

308 significantly lower MVH in YLC than BLC $(P=0.01)$. However, there was no significant

309 difference between YLS and BLC or BLS, thus a near significant difference was apparent

310 between the YLC and YLS groups $(P=0.06)$. However visually, the YLS microvilli surface

311 of the gut enterocytes appeared more densely arranged than for the YLC group that were more

312 fragmented in appearance in images $\mathrm{J}$ and I (Fig. 3), respectively. This was also observed for

313 lateral images of the microvilli brush border; A \& B (YLC) and C \& D (YLS) respectively.

314 No significant effect of lupin type, SSF presence or an interaction between the two dietary

315 variables was observed upon estimated total absorption surface area (TAS), at the

316 ultrastructural level. However the TAS of the YLC group appeared somewhat lower than the 317 other dietary groups

318 The relative feed $\operatorname{cost} / \mathrm{kg}$ of fish fed diets containing a commercial SSF product

319 (Synergen ${ }^{\mathrm{TM}}$ SSF) was lower than the feed used as the control (88, $92 \%$ vs. Control 100\%)

320 (Table 1). The data also indicate that Nile tilapia fed diets containing the SSF product

321 (Synergen ${ }^{\mathrm{TM}} \mathrm{SSF}$ ) recorded the best FCR and ECR values. The YLS diet had the lowest in total

322 feed cost and the best relative feed cost $/ \mathrm{kg}$ gain, while fish fed the control diet recorded the

323 highest in total feed cost $/ \mathrm{kg}$ fish gain.

\section{DISCUSSION}

325 The potential of Solid State Fermentation (SSF) products to improve aquaculture feeds

326 by releasing plant nutrients that are unavailable to fish and reducing Anti-Nutritional Factors

327 (ANFs) within specific plant feed ingredients requires more study to validate their efficiency 
328 in fish diets. The present trial was conducted to establish and document the effects of a 329 nutritional solution produced by a commercial SSF product (Synergen ${ }^{\mathrm{TM}}$ SSF) on Nile tilapia 330 production and health when supplemented to diets containing blue and yellow lupin as a UK 331 initiative to produce home grown plant crops for animal production and aquaculture in Europe. 332 We included both British grown lupin meal varieties (Blue and Yellow) at realistic inclusions 333 of $15 \%$. This was based on previously tested levels with success for several warm water fish 334 species. Of particular relevance to this study, it was confirmed by Abdel-Moneim and Yones 335 (2010) that up to 50\% of lupin kernel meal (LKM) can be included by replacing the fish meal 336 component in diets of juvenile red hybrid tilapia (Oreochromis niloticus x O. mossambicus) 337 with positive effects on growth performance and nutrient utilization. Our Lupin (SSF-free) 338 based diets all gave comparable results to Abdel-Moneim and Yones (2010) that was evident 339 of lupins being as good a plant protein concentrate for conventional soybean for tilapia. It is 340 recognised too that it might also be desirable to run experimental diets against a range of 341 practical commercial tilapia diets for comparisons in practical conditions.

342 In the present study, comparisons between the lupin basal diets seems to suggest that there was 343 no significant effect of lupin kernel meal (LKM) type on performance. This appears to be in 344 agreement with findings by Glencross et al. (2006), whom did not observe any difference in 345 performance between rainbow trout fed yellow (cv. Wodjil) or narrow-leaf (cv. Gungarru) lupin 346 protein concentrates. Furthermore, a later study by Glencross et al. (2011), did not detect any 347 significant difference in performance between rainbow trout fed between yellow and narrow348 leaf (blue lupin) varieties. On the contrary, Salini and Adams (2014) reported that the FCR of 349 fish fed yellow lupin cultivar (Pootalong) was higher than all other dietary treatments and 350 significantly greater than the narrow-leaf lupin (cv. Jindalee); indicating that Pootalong (YL) 351 was of lower nutritional quality. Furthermore, Sharawy et al (2016) observed that fish meal 352 (FM) could be substituted by solid state fermented soybean meal (SSF-SBM) with yeast, The 
results of this latter work indicate that SSF-SBM with yeast, S. cerevisiae, is an acceptable alternative plant protein source that can replace up to $50 \%$ of dietary FM protein in diets of Indian white shrimps yields comparable growth and production, and is as cost effective, as the control diet. The present results with tilapia indicated that lupin meals treated by the SSF containing natural exogenous enzymes likely improved the digestibility of NSP, overall feed efficiency and reduce the levels of toxic alkaloids, a factor which could limit the acceptance of 359 lupin seeds (Glencross and Hawkins, 2004). It should be noted that due to the difficulty in obtaining faeces from tilapia under the conditions defined, it was not possible to report coefficients of digestibility in the study but this would be considered in future experiments with lupin incorporation together with SSF or other exogenous feed enzyme supplementation and using a suitable inert marker such as yttrium oxide.

The YLC diet in the present study resulted in numerically inferior SGR, FCR and PER values compared to the BLC diet, and these findings are consistent with those of Salini and 366 Adams (2014). Following inclusion of Synergen ${ }^{\mathrm{TM}}$ (SSF), the fish showed significant improvements to their overall weight gain, final weight and SGR and FCR in both lupin varieties tested. Ilham et al (2018) also noted that the growth of barramundi (Lates calcarifer) fed fermented lupin meal (FLM) attained similar growth to fish fed a fish meal based diet 370 indicating that fermented lupin meal had a potential to substantially replace $75 \%$ FM protein 371 in the diets of barramundi.

372 In the present study, no statistically significant differences in Protein Efficiency Ratio, 373 (PER) were found among the dietary treatments of Nile tilapia fed SSF inclusion but trends 374 appeared to display a numerical increase in PER of SSF-fed fish, particularly with regards to 375 the yellow lupin diet. Furthermore, Yadava et al. (2009) found that Allzyme ${ }^{\circledR}$-SSF was 376 observed to improve protein efficiency in a practical broiler formulation, indicating that solid377 state fermentation processes and exogenous enzymes can impart residual bioactivity capable 
378 of aiding in the animal's efficacy of converting protein to body mass. Our growth performance 379 and feed utilisation data compared well as for tilapia fed lupins by Moneim and Yones (2010) 380 indicating that our basal diet of $15 \%$ lupin was a satisfactory reference diet for SSF evaluation.

381 It should be cautioned that there is no specific control or reference diet for tilapia available as 382 ingredient formulations vary extensively. It was therefore deemed appropriate to compare two 383 types of lupin meals at fixed levels with and without SSF addition.

384 Extensive reviews of carbohydrate utilisation by fish have been published by a number 385 of authors, the general consensus affirming that complex carbohydrates are poorly digested 386 outside of strictly herbivorous fish but lower molecular weight carbohydrates (i.e. mono- and 387 disaccharides) tend to be readily available (Krogdahl et al., 2005). Carbohydrates which are 388 not degraded may impart undesirable characteristics upon the GIT and its contents, such as 389 increasing intestinal viscosity (Bedford and Partridge, 2010), thus classifying many of them as 390 fibre type ANFs. However, if low molecular-weight carbohydrates become available to the 391 animal then they may be utilised as metabolisable energy, reducing the metabolic burden of 392 gluconeogenesis and subsequently leading to a carbohydrate induced protein-sparing effect.

393 This has been widely acknowledged as effective in a vast number of finfish species, including 394 Nile tilapia, as reviewed by Krogdahl et al. (2005). Glencross et al. (2003) examined the 395 influence of lupin oligosaccharides on nutrient digestibility in rainbow trout, concluding that 396 removal of these components by $\alpha$-galactosidase significantly improves nitrogen digestibility 397 and that monosaccharide derivatives of this process are readily absorbed by the animal. 398 Galactosidase has been reported as secreted by A. niger during solid-state fermentation of 399 wheat bran (Passos et al., 2015), thus there is a strong possibility of such occurrences during 400 this study. In the present study with tilapia, the Synergen ${ }^{\mathrm{TM}}$ product used is a natural solid-state 401 fermentation complex of Aspergillus niger that contains residual enzyme activity as described 402 by Diógenes et al (2018). SSF type products contain a heterogeneous complex of residual 
enzymes e.g. xylanases, cellulases, amylases and proteases as well as phytases liberated by the 404 action of $A$ niger on the substrate during fermentation. Because all the enzymes have been 405 produced together during the SSF process, they work in synergy resulting in a greater nutrient 406 release than with individual enzymes or cocktails of different enzymes as demonstrated 407 successfully for piglets (Taylor-Pickard, 2014). More nutrients released from the diet means 408 for example, that more energy is released which can be used by the gastro-intestinal cells and 409 stimulating localised ultra-structure development such as enterocyte micro-villi.

410 At the gastrointestinal level of the tilapia undergoing the various dietary treatments, 411 distinct trends in epithelial Enterocyte Height (EH), relating to the presence or absence of SSF, 412 were identified in the current study. Whilst both the control diets displayed no marked 413 alteration to EH until the mid-point of the trial, significant heightening of enterocytes lining 414 the gut was indicated thereafter; meanwhile, the opposite trend was the case of the SSF diets.

415 Overall, the present study provides a quantitative appraisal of enterocyte height from a view of 416 developmental progressions, rather than a final suggested change due to respective treatment 417 effect. These fluctuations are proposed as an indication of dietary adaption; this could be due 418 to nutrient provision and possibly establishment of equilibria within the gut microbiome 419 although not tested in this study.

420 In terrestrial mono-gastric animals, some studies have indicated that exogenous enzyme 421 sources can liberate sufficient bioavailable nutrients to trigger enhanced performance without 422 effect upon epithelial parameters (Amerah et al., 2008; Owens et al., 2008). Conversely, the 423 results of this study indicate that exogenous facilitators of fermentation within the gut can elicit 424 a positive effect upon epithelial cells and they demonstrate effectively that time is a critical 425 factor in confidently identifying whether additives of this kind modulate morphology.

426 Perimeter ratios of the midgut (PR) were observed to change noticeably from the initial 427 measurements in the first half of the investigation. This indicates that the functional border of 
428 the midgut, in all treatments, increased in surface area after the feeding of the commercial diet 429 was ceased and tilapia were fed diets containing lupins and SSF for the duration of the trial.

430 Conversely, Smulikowska et al., (2014) reported that increasing levels of both yellow and 431 narrow-leaf blue lupin caused reducing effects to the potential absorptive area of the intestine 432 in broilers. The results of this study are of interest as greater surface area is routinely considered 433 to be a beneficial characteristic but it appears it may not always necessarily be indicative of a 434 higher-quality diet formulations. By day 26, all treatments were almost indistinguishable in 435 their relative gut surface area, which was by and large maintained until day 49 in the YLC, 436 BLC and BLS treatments. However the continuation to day 49 saw YLS-fed fish display a 437 substantial increase in functional surface area compared to day 26 , thus also a divergence away 438 from the other treatments. This seems to correspond with findings by Olkowski et al. (2010), 439 who detected significant elongation of villi in the intestine of broilers fed yellow lupin-based 440 diets supplemented with non-starch polysaccharide degrading enzymes. Overall, the present 441 results for tilapia appear to show a more pronounced effect of lupins upon gut macrostructure 442 than has previously been reported in finfish (Omnes et al., 2015; Refstie et al., 2006; Glencross 443 et al., 2004). To the author's knowledge, no known studies have examined tissue at an 444 ultrastructural level following feeding of lupin diets to monogastric species, let alone in 445 partnership with fermentation products. Therefore, cross-literary comparisons are difficult. 446 Yellow lupin appeared to elicit poorer potential for functional surface area at an ultrastructural 447 level, compared with narrow-leaf lupin. Thicker microvilli appeared to reduce potential for 448 higher density, whilst the microvilli provided less surface area due to a reduced length. There 449 was no apparent influence of improvement to these parameters when the yellow lupin diet was 450 supplemented with SSF. However, the fact that YLC group had significantly shorter microvilli 451 than the BL groups but the YLS average microvilli length was comparable to the BL groups 452 suggests a positive effect may still have occurred. These results seemed to display trends 
453 towards improved absorption surface area (TAS) in the YLS, with no noticeable difference

454 with the narrow-leaf blue lupin fed tilapia. This suggests that negative effects of yellow lupin

455 upon gut ultrastructure can be mitigated to an appreciable extent by SSF inclusion such as

456 Synergen ${ }^{\mathrm{TM}}$ and allowing greater surface area potential for assimilation of nutrients. Promotion

457 of these kinds of ultrastructural characteristics has also been associated with low molecular-

458 weight prebiotics (MOS) Dimitroglou et al. (2009), supporting the benefits of non-starch

459 polysaccharide degradation by exogenous enzymes. Considering all of these patterns, it would

460 be highly beneficial for future studies to quantify effects upon nutrient digestibility and

461 modulation of the gut microbiota in tilapia and in other commercially important fish species

462 fed various grains, plant protein concentrates and seed meals in combination with SSF products.

463 It was evident that the commercial SSF product evaluated in this study significantly

464 improved several production parameters for tilapia and can play a positive role in contributing

465 to cost effective and sustainable diet formulations for aquaculture.

\section{CONCLUSION}

467 To our best knowledge, this study is the first study of its kind investigating the inclusion

468 of a solid-state fermentation product in finfish diets containing lupin. Without SSF-inclusion,

469 the narrow-leaf lupin appears to elicit preferable production characteristics compared to yellow

470 lupin. The result indicated that inclusion of the specific commercial solid- state fermentation,

471 SSF product evaluated in this study can be an effective means of promoting better performance

472 and to some extent, improving gut morphology, most probably due to a supply of exogenous

473 bioactive components capable of degrading indigestible dietary fractions in a lower quality

474 plant feed ingredient. This appeared most pronounced when SSF was added to a yellow lupin

475 diet in tilapia. Clearly, there is scope for more extensive studies with high value carnivorous

476 species such as salmonids (rainbow trout and salmon) as well as marine fish e.g. seabass,

477 seabream, to improve the value of plant ingredients in diet formulations. SSF products such as 
478 Synergen ${ }^{\mathrm{TM}}$ have promising capacity to improve fish growth and feed performance as well as 479 enhancing gut integrity and ultimately the health and welfare of farmed fish. They will also 480 likely impart the benefit of reducing environmental impact through more efficient digestion 481 and may provide an economic gain in fish production costs. Tilapia production in Europe is 482 being realised and there are several feed manufacturers engaged in specialised diets for this 483 species as well as for the export market particularly to Africa. The use of sustainable plant 484 ingredients like lupins can help reduce our soy bean import dependency and coupled with SSF 485 supplementation can be a positive asset to meet this agenda.

ACKNOWLEDGMENTS

487 488
This work was supported by Innovate UK as part of the Lupins in UK Agriculture and Aquaculture initiative. The authors also wish to acknowledge Alltech (KY) for their contribution to the project and studentship, Soya UK and Alvan Blanch, UK for the supply of ingredients.

\section{REFERENCES}

Abdel-Moneim A. M. Yones (2010) Effect of lupin kernel meal as plant protein source in diets of red hybrid tilapia (Oreochromis niloticus x O. mossambicus), on growth performance and nutrients utilization. African J. Biol. Sci., 6 (1): 1-16 (2010) ISSN $1687-4870$

Amerah, A.M., Ravindran, V., Lentle, R.G. \& Thomas, D.G. (2008). Influence of particle size and xylanase supplementation on the performance, energy utilisation, digestive tract 
503

504

505

506

507

508

509

510

511

512

513

514

515

516

517

518

519

520

521

522

523

524

525

526

527

parameters and digesta viscosity of broiler starters. British Poultry Science, 49, 455462.

AOAC (2016). Official methods of analysis (20 th edition). Washington DC, USA: AOAC International.

Bedford, M.R. \& Partridge, G.G. (eds) (2010). Enzymes in farm animal nutrition. CAB International, Oxfordshire, UK.

Bartkiene, E, Krungleviciute, V, Juodeikiene, G, Vidmantiene, D \& Maknickiene, Z (2015). Solid state fermentation with lactic acid bacteria to improve the nutritional quality of lupin and soya bean. Journal of the Science of Food and Agriculture. 95(6):133613342

Binh Van V., Dien P.B., Huy Q.N. \& Fotedar R. (2015). Optimized fermented lupin (Lupinus angustifolius) inclusion in juvenile barramundi (Lates calcarifer) diets. Aquaculture, $444,62-69$.

Bowyer, P. H. El-Haroun, E.R. \& Davies, S.J (2019). Dietary nucleotides enhance intestinal functional topography in European seabass (Dicentrarchus labrax). Aquaculture research. DOI: 10.1111/are.14078

Brown, B.A. (ed) (1988). Routine hematology procedures. Leo and Febiger, Philadelphia, PA, USA.

Chien, Y.H. \& Chiu Y.H. (2003). Replacement of soybean (Glycine max (L.) Merrill) meal by lupin (Lupinus angustifolius) seed meal in diet for juvenile tilapia (Oreochromis niloticus x O-aureus) reared indoors. Aquaculture Research, 34, 1261-1268.

Daniel N. (2017). Status of aquaculture with respect to nutrition and feed. International Journal of Fisheries and Aquatic Studies; 5(1):333-345.

Daniel, N. (2018). A review on replacing fish meal in aqua feeds using plant protein sources. International Journal of Fisheries and Aquatic Studies; 6 (2): 164-179 
528 Davies, S.J., Laporte, S.L., Gouveia, J., Salim, H.S., Woodgate, S.M. \& El-Haroun, E.R. (2019).

529 Validation of novel processed animal proteins (mono-PAPS) within experimental

530 diets for juvenile gilthead sea bream (Sparus aurata L.) as primary fish meal

531 replacers. Aquaculture Nutrition. 25 (1): 225-238

532 Demers N.E. \& Bayne C.J. (1997). The immediate effects of stress on hormones and plasma

533 lysozyme in rainbow trout. Developmental and Comparative Immunology, 21, 363-

$534 \quad 373$.

535 Dimitroglou A., Merrifield D.L., Moate R., Davies S.J., Spring P., Sweetman J. \& Bradley G.

536 (2009). Dietary mannan oligosaccharide supplementation modulates intestinal

537 microbial ecology and improves gut morphology of rainbow trout, Oncorhynchus

538 mykiss (Walbaum). Journal of Animal Science, 87, 3226-3234.

539 Alexandre F. Diógenes, Carolina Castro, Marta Carvalho, RuiMagalhães, Tassia T. Estevão-

540 Rodrigues, Cláudia R. Serra, Aires Oliva-Teles, Helena Peres (2018) Exogenous

541 enzymes supplementation enhances diet digestibility and digestive function and

542 affects intestinal microbiota of turbot (Scophthalmus maximus) juveniles fed

543 distillers' dried grains with solubles (DDGS) based diets. Aquaculture 486, 42-50

544

545 El-Husseiny, O.M., Mohamed I. Hassana, El-Harouna, E.R. \& Suloma, A. (2018). Utilization

546 of poultry by-product meal supplemented with L-lysine as fish meal replacer in the

547 diet of African catfish Clarias gariepinus (Burchell, 1822). Journal of applied

$548 \quad$ Aquaculture, $30(1), 63-75$

549 FAO (2016). The state of world fisheries and aquaculture. Report of the fisheries and $550 \quad$ aquaculture department, Rome Italy. 
551 Glencross B.D., Boujard T. \& Kaushik S.J. (2003). Influence of oligosaccharides on the

552

553

554

555

556

557

558

559

560

561

562

563

564

565

566

567

568

569

570

571

572

573

574

575 digestibility of lupin meals when fed to rainbow trout, Oncorhynchus mykiss. Aquaculture, 219, 703-713.

Glencross B., Evans D., Hawkins W. \& Jones B. (2004). Evaluation of dietary inclusion of yellow lupin (Lupinus luteus) kernel meal on the growth, feed utilisation and tissue histology of rainbow trout (Oncorhynchus mykiss). Aquaculture, 235, 411-422.

Glencross B., Hawkins W., Evans D., Rutherford N., Dods K., Maas R., McCafferty P. \& Sipsas, S. (2006). Evaluation of the nutritional value of prototype lupin protein concentrates when fed to rainbow trout (Oncorhynchus mykiss). Aquaculture, 251, 66-77.

Glencross B., Rutherford N. \& Hawkins W. (2011). A comparison of the growth performance of rainbow trout (Oncorhynchus mykiss) when fed soybean, narrow-leaf or yellow lupin meals in extruded diets. Aquaculture Nutrition, 17, 317-325.

Goda, A., Srour, T., Omar, E., Mansour, A., Baromh, M., Mohamed, S., El-Haroun, E.R. \& Davies, S.(2019). Appraisal of a high protein distiller's dried grain (DDG) in diets for European sea bass, Dicentrarchus labrax fingerlings on growth performance, haematological status and related gut histology. Aquaculture nutrition (In Press)

Hassaan, M., Goda, A.S. \& Kumar, V. (2017). Evaluation of nutritive value of fermented deoiled physic nut, Jatropha curcas, seed meal for Nile tilapia, Oreochromis niloticus fingerlings. Aquaculture Nutrition. 23, 571-584.

Hassan, M., El-Haroun, E.R, \& Davies, S. (2018). Growth and physiological responses of Nile tilapia, Oreochromis niloticus to dietary fermented sunflower meal with Saccharomyces cerevisiae and Bacillus Subtilis. Aquaculture 495:592-601.

Hassaan, M.S., El-Sayed, A.I.M., Soltan, M.A., Iraqi, M.M., Goda, A.M., Davies, S.J., ElHaroun, E.R. \& Ramadan, H.A. (2019). Partial dietary fish meal replacement with 
576

577

578

579

580

581

582

583

584

585

586

587

588

589

590

591

592

593

594

595

596

597

598

cotton seed meal and supplementation with exogenous protease alters growth, feed performance, hematological indices and associated gene expression markers $(\mathrm{GH}$, IGF-I) for Nile tilapia, Oreochromis niloticus. Aquaculture, 503: 282-292.

Hooge D.M., Pierce J.I., McBride K.W. \& Rigolin P.J. (2010). Meta- analysis of broiler chicken trials using diets with or without Allzyme ${ }^{\circledR}$ SSF enzyme complex. International Journal of Poultry Science, 9, 819-523.

Ilham, I; H, Fitriska \& Fotedar, R. (2018). Growth, enzymatic glutathione peroxidase activity and biochemical status of juvenile barramundi (Lates calcarifer) fed dietary fermented lupin meal supplemented with organic selenium, aquaculture research, https://doi.org/10.1111/are.13444

Kim J.C., Pluske J.R. \& Mullan B.P. (2008). Nutritive value of yellow lupins (Lupinus luteus L.) for weaner pigs. Australian Journal of Experimental Agriculture, 48, 1225-1231.

Kim J.C., Mullan B.P., Nicholls R.R. \& Pluske J.R. (2011). Effect of Australian sweet lupin (Lupinus angustifolius L.) inclusion levels and enzyme supplementation on the performance, carcass composition and meat quality of grower/finisher pigs. Animal Production Science, 51, 37-43.

Krogdahl A., Hemre G.I. \& Mommsen T.P. (2005). Carbohydrates in fish nutrition: digestion and absorption in postlarval stages. Aquaculture Nutrition, 11 (2): 103-122

Lucht J.M. (2015). Public acceptance of plant biotechnology and GM crops. Viruses-Basel, 7, 4254-4281.

Mercedes L.M., Stoddard F.L., Annicchiarico P., Frias J., Martinez-Villaluenga C., Sussman D., Duranti M., Seger A., Zander P.M. \& Pueyo J.J. (2015). The future of lupin as a protein crop in Europe. Frontiers in Plant Science, 6. 
599 Michael, R.F., Lee, Sarah, P, Hannah, R. F., Vince, J, T., Dave, K \& Leemansa, T, B. (2016). 600 The potential of blue lupins as a protein source, in the diets of laying hens. Veterinary $601 \quad$ and Animal Science, 29-35

602 NRC (2011). Nutrient Requirements of Fish. National Academies Press, Washington, USA.

603 Olkowski B., Janiuk I. \& Jakubczak A. (2010). Effect of Enzyme Preparation with Activity 604 Directed Towards Degradation of Non Starch Polysaccharides on Yellow Lupine 605 Seed Based Diet for Young Broilers. Acta Veterinaria Bmo, 79, 395, 402.

606 Olkowski B. (2011). Lupin as primary protein source in young broiler chicken diets: Effect of 607 enzymes preparations catalyzing degradation of non-starch polysaccharides or 608 phytates. World Journal of Microbiology \& Biotechnology, 27, 341-347.

609 Omnes M.H., Silva F.C.P., Moriceau J., Aguirre P., Kaushik S. \& Gatesoupe F.J. (2015). 610 Influence of lupin and rapeseed meals on the integrity of digestive tract and organs 611 in gilthead seabream (Sparus aurata L.) and goldfish (Carassius auratus L.) juveniles. 612 Aquaculture Nutrition, 21, 223-233.

613 Owens B., Tucker L., Collins M.A. \& McCracken K.J. (2008). Effects of different feed 614 additives alone or in combination on broiler performance, gut microflora and ileal 615 histology. British Poultry Science, 49, 202-212.

616 Passos A.A., Andrade C., Phillips C.E., Coffey M.T. \& Kim S.W. (2015). Nutrient value of 617 spray field forages fed to pigs and the use of feed enzymes to enhance nutrient 618 digestibility. Journal of Animal Science, 93, 1721-1728.

619 Taylor-Pickard, J (2014) Helping the gut mature by promoting enzymes, Pig Progress special $620 \quad-$ Piglet Health, Background Jun 17, 2014 pp1

621 Rajeev, R. \& Bavitha, M. (2015). Lupins-An alternative protein source for aquaculture diets. 622 International Journal of Applied Research 2015; 1(3): 4-8 
623 Rawling M.D., Merrifield D.L., Snellgrove D.L., Kuehlwein H., Adams A. \& Davies S.J,

624

625

626

627

628

629

630

631

632

633

634

635

636

637

638

639

640

641

642

643

644

645

646

(2012). Haemato-immunological and growth response of mirror carp (Cyprinus carpio) fed a tropical earthworm meal in experimental diets. Fish and Shellfish Immunology, 32, 1002-1007.

Refstie S., Glencross B., Landsverk T., Sorensen M., Lilleeng E., Hawkins W. \& Krogdahl A. (2006). Digestive function and intestinal integrity in Atlantic salmon (Salmo salar) fed kernel meals and protein concentrates made from yellow or narrow-leafed lupins. Aquaculture, 261, 1382-1395.

Rezende S.T. (2012). Effects of enzyme complex SSF (solid state fermentation) in pellet diets for Nile tilapia. Rev. Bras. Zootecn., 41, 2139-2143.

Salini M.J. \& Adams L.R. (2014). Growth performance, nutrient utilisation and digestibility by Atlantic salmon (Salmo salar L.) fed Tasmanian grown white (Lupinus albus) and Sharawy, Z., Goda, A, M. \& Hassaan, M.S. (2016). Partial or total replacement of fish meal by solid state fermented soybean meal with Saccharomyces cerevisiae in diets for Indian prawn shrimp, Fenneropenaeus indicus, Postlarvae. Animal Feed Science and Technology 212 (2016) 90-99

Smulikowska S., Konieczka P., Czerwinski J., Mieczkowska A. \& Jankowiak J. (2014). Feeding broiler chickens with practical diets containing lupin seeds (L. angustifolius or L. luteus): effects of incorporation level and mannanase supplementation on growth performance, digesta viscosity, microbial fermentation and gut morphology. Journal of Animal and Feed Sciences, 23, 64-72.

van Barneveld R.J. (1999). Understanding the nutritional chemistry of lupin (Lupinus spp.) seeds to improve livestock production efficiency. Nutrition Research Reviews, 12, 203-230. 
647 Yadava P.K., Niranjan P.S., Udebeyir S.K. \& Verma D.N. (2009). Performance of Broiler 648 Chicken as Affected by Varying Levels of Multi Enzyme Supplementation. Animal 649 Nutrition and Feed Technology, 9, 103-109.

650 Yeheyis L., Kijora C., van Santen E., Wink M., Danier J. \& Peters K.J. (2012) Crude protein, 651 amino acid and alkaloid contents of annual sweet lupin (Lupinus spp. L.) forages 652 and seeds grown in Ethiopia. Experimental Agriculture, 48, 414-427. 